\title{
The Influence of Racio-Ethnicity on Gingival Thickness in Dravidian and Mongoloid Population- A Pilot Study
}

\author{
Prabhuji Munivenkatappa Lakshmaiah Venkatesh ${ }^{1}$, Karthikeyan Bangalore Varadhan², Kishore Hadal ${ }^{3}$, \\ Ameya Moghe ${ }^{4}$, Kamedh Choudhry ${ }^{5}$, Irfana S. Sabrawala ${ }^{6}$
}

${ }^{1}$ Professor and HOD, Department of Periodontics, Krishnadevaraya College of Dental Sciences, Bengaluru, Karnataka, India. ${ }^{2}$ Reader, Department of Periodontics, Krishnadevaraya College of Dental Sciences, Bengaluru, Karnataka, India.

${ }^{3}$ Reader, Department of Periodontics, Krishnadevaraya College of Dental Sciences, Bengaluru, Karnataka, India.

${ }^{4}$ Former Postgraduate Student, Department of Periodontics, Krishnadevaraya College of Dental Sciences, Bengaluru,

Karnataka, India. ${ }^{5}$ Former Postgraduate Student, Department of Periodontics, Krishnadevaraya College of Dental

Sciences, Bengaluru, Karnataka, India. ${ }^{6}$ Former Postgraduate Student, Department of Periodontics, Krishnadevaraya College of Dental Sciences, Bengaluru, Karnataka, India.

\section{ABSTRACT}

\section{BACKGROUND}

Variations in gingival phenotypes may be influenced by tooth shape, position, age and gender as well as the involvement of confounding factors such as racial and genetic factors which in turn influence the clinical and aesthetic outcome of certain periodontal procedure. Therefore, it is important to comprehend if there is any racial influence on gingival thickness. The current study is designed which is the first of its kind to assess the probable role of Mongoloid and the Dravidian races on gingival thickness if any. The aim of the study was to evaluate as to whether there was any difference in the gingival biotype amongst the Mongoloid and the Dravidian races.

\section{METHODS}

A total of 100 systemically healthy individuals in the age group ranging of 18-30 years belonging to two different ethnic groups; Mongoloid (25 males and 25 females) and Dravidians (25 males and 25 females) were randomly selected for the study from the outpatient Department of Periodontology, Krishnadevaraya College of Dental Sciences, Bangalore, from January to May 2016 for the study. Gingival thickness was assessed in the maxillary and mandibular anteriors at the mid papillary and mid buccal sites by modified digital vernier calliper.

\section{RESULTS}

The difference in mean gingival thickness between the Dravidian (maxilla: $1.73 \pm 0.09 \mathrm{~mm}$; mandible: $1.40 \pm 0.15 \mathrm{~mm}$ ) and Mongoloid (maxilla: $1.88 \pm 0.15 \mathrm{~mm}$; mandible: $1.60 \pm 0.18 \mathrm{~mm}$ ) population was statistically significant.

\section{CONCLUSIONS}

Within the limitations of the study it can be concluded that racio-ethnicity could have a positive influence on the gingival biotype. Clinicians should therefore take into consideration the possible influence of racial factor while determining the gingival biotype during the diagnostic and prognostic planning.

\section{KEY WORDS}

Gingival Thickness, Digital Vernier Calliper, Biotype
Corresponding Author:

Dr. Karthikeyan Bangalore Varadhan, Department of Periodontics,

Krishnadevareya College of Dental

Sciences, Bengaluru, Karnataka, India.

E-mail: drkarthikeyarbv@gmail.com

DOI: $10.14260 / j e m d s / 2019 / 588$

Financial or Other Competing Interests: None.

How to Cite This Article:

Venkatesh PML, Varadhan KB, Hadal K, et al. The influence of racio-ethnicity on gingival thickness in dravidian and mongoloid population- a pilot study. J. Evolution Med. Dent. Sci. 2019;8(35): 2708-2712, DOI:
Submission 26-06-2019,

Peer Review 14-08-2019,

Acceptance 22-08-2019,

Published 02-09-2019. 


\section{BACKGROUND}

In recent years, a substantial interest has arisen to determine the precise diagnosis of gingival tissue biotype since it is of paramount importance in designing an appropriate treatment plan and attaining a predictable aesthetic outcome. ${ }^{1}$ According to studies, a direct correlation exists between the biotype of the gingiva and the susceptibility to gingival recession following surgeries and restorations. ${ }^{2,3}$ The so - called thick flat biotype demonstrates more soft tissue regain as compared with a thin-scalloped biotype that shows higher prevalence of gingival recession. 4,5 Thin biotype also exhibit dehiscence and fenestrations due to thin bony housing and overlying soft tissues. ${ }^{6}$ Normally, amongst different individuals, there is a considerable variation in thickness and width of the facial gingiva that gives rise to the presumption that, disparate gingival phenotypes might exist in any adult population.5,7 Further, inter individual variability among different tooth type may be genetically determined or influenced by tooth shape, position and size and biological phenomenon such as growth, age and gender. ${ }^{8}$

In addition, involvement of confounding factors (Racial and genetic factors) have also been reported to influence the gingival thickness as it is considered as one of the significant clinical predictors of certain periodontal procedures. ${ }^{9}$ In a study by Studer et al, it was noted that there is a difference in the gingival thickness in the region of canine and premolars between Asian and Caucasian population and they attributed that this finding could be due to racial variations. ${ }^{10}$ Thus it becomes essential to comprehend the importance of racial influence on gingival thickness on various sub continents of the world. India being the Land of Diversity has two major racio-ethnic groups, identified as the Ancestral South Indians (ASI) and Ancestral North Indians (ANI) who correspond to the Dravidian population of southern India and the IndoAryan population of northern India (e.g. Mongoloid population). ${ }^{9}$ Till date, there are no studies conducted to explore the influence of race on gingival thickness on these racio- ethnic groups. Hence, the current study is designed which is first of its kind to assess the probable role of Mongoloid and the Dravidian races on gingival thickness if any. (Placeholder1).

\section{METHODS}

Before initiation of the study, power analysis was completed. The sample size of 100 (50 in each group) was determined using a $\mathrm{G}$ power software with $\alpha$ maintained at 0.5 and power set at $90 \%$. Therefore, a total of 100 systemically healthy individuals of age groups ranging from 18 years to 30 years belonging to two different ethnic groups; Mongoloid (25 males and 25 females) and Dravidians (25 males and 25 females) were selected from the outpatient Department of Periodontology, Krishnadevaraya college of Dental sciences, Bangalore from January to May 2016 for the study. The inclusion of individuals was on the basis of individual's name, place of birth, mother tongue, self-identification and healthy gingiva with no loss of attachment. Strictly, individuals having healthy periodontal tissues with $\leq 20 \%$ bleeding on probing and presence of all anterior teeth in both upper and lower jaws were included to control the factors influencing the gingival thickness. The exclusion criteria considered were gingival recession in the anterior teeth, pregnancy and lactation, smokers, systemic disease, use of any medication such as cyclosporin A, calcium channel blockers and phenytoin possibly affecting the periodontal tissues and extensive restorations. Patients with previous orthodontic treatment, malpositioned teeth or soft tissue surgeries with grafts were also excluded from the study. The selected patients were explained about the study and were made to sign an informed consent form prior to commencement of the study. The study was conducted according to the 1975 Helsinki Declaration, as revised in 2000 and ethical board clearance was obtained from an institutional review board affiliated to Rajiv Gandhi University of Health Sciences, Bangalore, India. Oral prophylaxis was performed for all subjects followed by giving them oral hygiene instructions.

\section{Measurements}

The gingival thickness was examined for the maxillary and mandibular central and lateral incisors and canines. Two measurements were recorded on each tooth. The measurements were: (a) halfway between the free gingival groove and mucogingival junction, midbuccally $(\mathrm{MB})$ in the attached gingiva (Point $\mathrm{A}$ ) and (b) in the middle of the interdental papillary region (MP) on the facial aspect of the gingiva (Point B) (Figure 1).

\section{Measurement with Digital Vernier Calliper (DVC)}

A marking pencil was used to mark the measurement points on the facial aspect of the gingival. The facial gingiva was anaesthetized with topical lignocaine and the gingival thickness was assessed by using a DVC with a $0.01 \mathrm{~mm}$ calibration. Since, the jaws of the DVC were thick thereby making it difficult to be placed on the gingival tissue directly, the instrument was modified in such a way that by turning the knob located just above the digital output screen, a pointed blade tip would emerge from the other end of the instrument. (The knob was used to control the extent to which the pointed blade tip would emerge from the other end). This narrow-pointed end of the instrument was used to completely pierce through the marked point perpendicular to the facial gingiva until bony resistance was felt in order to assess the gingival thickness (Figure 2). The accurate corresponding value of the gingival thickness in point millimetres was displayed on the digital output screen of the instrument (Figure 3 and 4). To ensure the reliability of the assessment performed by the digital vernier caliper, a well experienced single calibrated examiner evaluated the gingival biotype for every patient. Further, to standardize the location, insertion and angulation of the DVC an acrylic stent was fabricated with placement of orthodontic molar tubes perpendicular to the long axis of the tooth at the predetermined points as shown in Figure 1, Figure 3 and Figure 4.

\section{Statistical Analysis}

The data collected was entered in Microsoft Excel and Statistical analyses were performed using the Statistical 
Package for Social Science (SPSS Ver. 10.5) software. ShapiroWilks test was done to test the normalcy of the data and the data was found to be normally distributed. Therefore, parametric statistical tests were applied. Student $t$ test was used for intergroup and intragroup analysis. $p$ value $\leq 0.05$ was considered to be statistically significant.
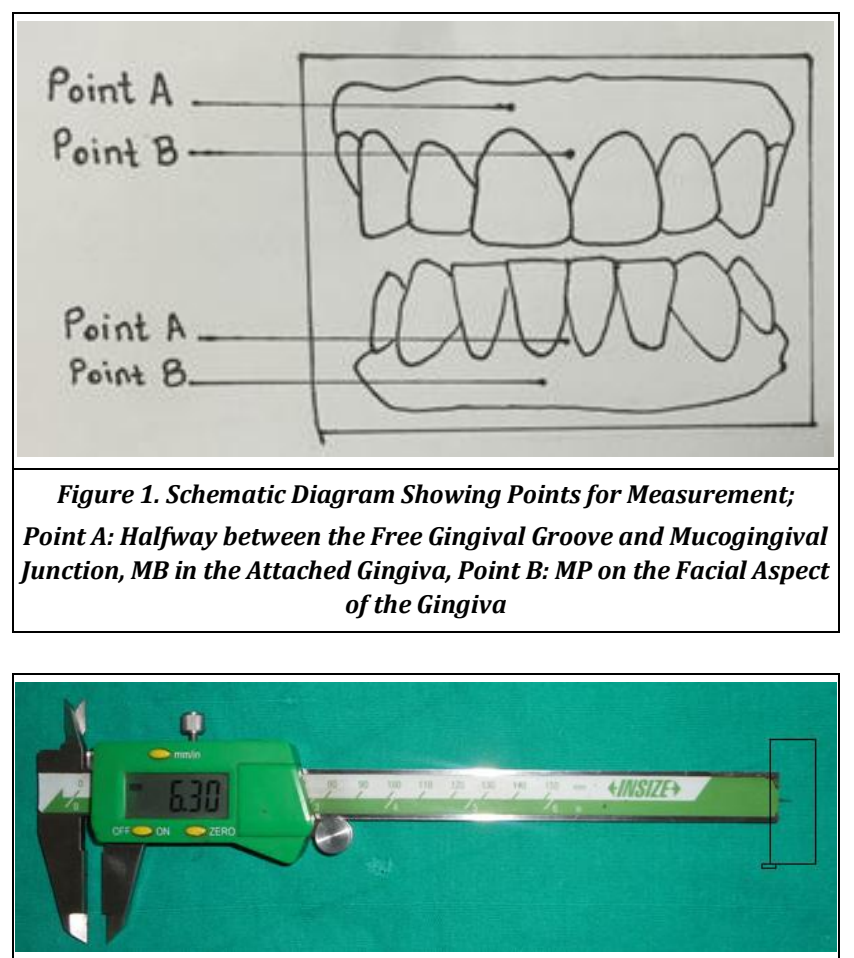

Figure 2. Modified Digital Vernier Calliper used for Assessing Gingival Thickness

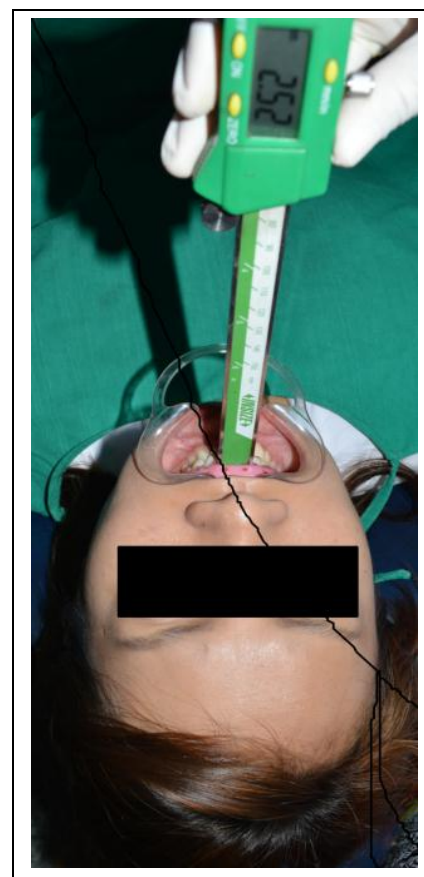

Figure 3. Placement of the Modified Digital Vernier Calliper for Measuring the Gingival Thickness in the Maxillary Mid buccal Region for Every Patient

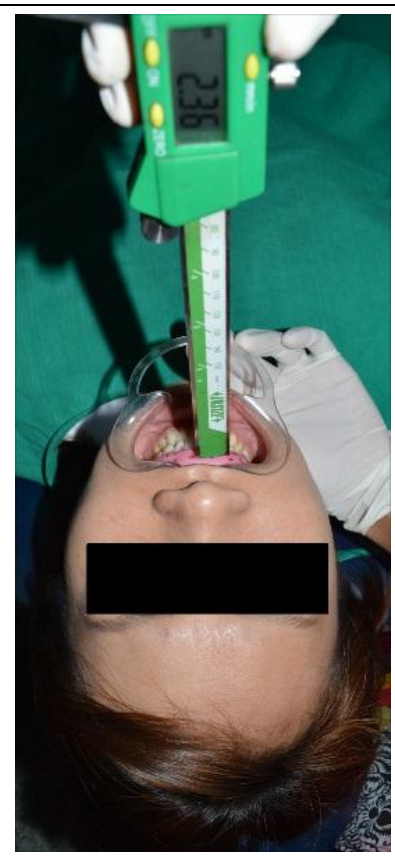

Figure 4. Placement of the Modified Digital Vernier Calliper for Measuring the Gingival Thickness in the Maxillary Mid Papillary Region for Every Patient

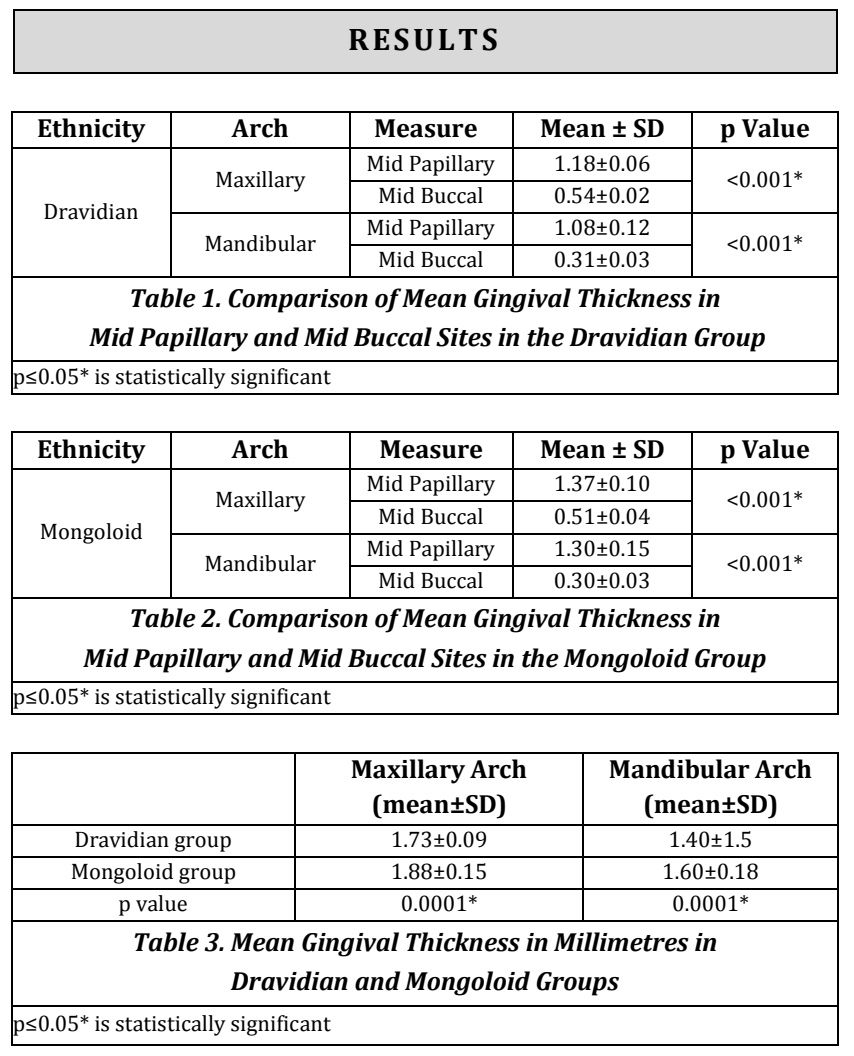

\begin{tabular}{|c|c|c|c|c|c|c|c|}
\hline & \multirow[t]{2}{*}{ Tooth } & \multicolumn{5}{|c|}{ Ethnic Groups } & \\
\hline & & \multicolumn{2}{|c|}{ Dravidian Group } & & \multicolumn{2}{|c|}{$\begin{array}{l}\text { Mongoloid } \\
\text { Group }\end{array}$} & p Value \\
\hline \multirow{7}{*}{ 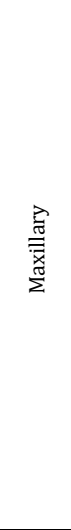 } & & 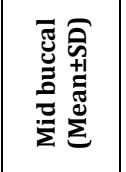 & 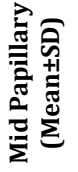 & $\begin{array}{l}\stackrel{*}{\circ} \\
\stackrel{0}{0} \\
\stackrel{0}{v}\end{array}$ & 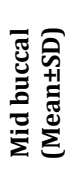 & 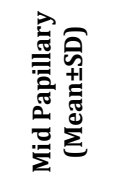 & \multirow{8}{*}{$<0.001^{*}$} \\
\hline & RC & $0.54 \pm 0.32$ & $\begin{array}{l}1.26 \pm \\
0.50 \\
\end{array}$ & & $\begin{array}{c}0.52 \pm \\
0.24 \\
\end{array}$ & $1.50 \pm 0.48$ & \\
\hline & RLI & $0.52 \pm 0.31$ & $\begin{array}{l}1.16 \pm \\
0.49\end{array}$ & $<0.001^{*}$ & $\begin{array}{c}0.45 \pm \\
0.24\end{array}$ & $1.32 \pm 0.37$ & \\
\hline & RCI & $0.56 \pm 0.29$ & $\begin{array}{l}1.10 \pm \\
0.47\end{array}$ & & $\begin{array}{c}0.57 \pm \\
0.29\end{array}$ & $1.29 \pm 0.35$ & \\
\hline & LCI & $0.58 \pm 0.28$ & $\begin{array}{c}1.16 \pm \\
0.49 \\
\end{array}$ & $\begin{array}{c}0.56 \pm \\
0.27 \\
\end{array}$ & $\begin{array}{c}0.56 \pm \\
0.27 \\
\end{array}$ & $1.29 \pm 0.42$ & \\
\hline & LLI & $0.54 \pm 0.36$ & $\begin{array}{l}1.14 \pm \\
0.50\end{array}$ & $\begin{array}{c}0.49 \pm \\
0.26 \\
\end{array}$ & $\begin{array}{c}0.49 \pm \\
0.26 \\
\end{array}$ & $1.29 \pm 0.48$ & \\
\hline & LC & $0.51 \pm 0.36$ & $\begin{array}{c}1.27 \pm \\
0.64\end{array}$ & $\begin{array}{c}0.49 \pm \\
0.22 \\
\end{array}$ & $\begin{array}{c}0.49 \pm \\
0.22 \\
\end{array}$ & $1.51 \pm 0.55$ & \\
\hline \multirow{6}{*}{ 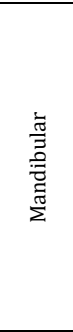 } & $\mathrm{RC}$ & $0.32 \pm 0.30$ & $\begin{array}{l}1.23 \pm \\
0.43 \\
\end{array}$ & $\begin{array}{c}0.26 \pm \\
0.15 \\
\end{array}$ & $\begin{array}{c}0.26 \pm \\
0.15 \\
\end{array}$ & $1.42 \pm 0.48$ & \\
\hline & RLI & $0.28 \pm 0.16$ & $\begin{array}{l}1.01 \pm \\
0.42 \\
\end{array}$ & $\begin{array}{l}0.32 \pm \\
0.23 \\
\end{array}$ & $\begin{array}{c}0.32 \pm \\
0.23 \\
\end{array}$ & $1.22 \pm 0.37$ & \multirow{5}{*}{$<0.001^{*}$} \\
\hline & RCI & $0.27 \pm 0.27$ & $\begin{array}{c}0.98 \pm \\
0.37\end{array}$ & $\begin{array}{c}0.31 \pm \\
0.20\end{array}$ & $\begin{array}{c}0.31 \pm \\
0.20\end{array}$ & $1.12 \pm 0.43$ & \\
\hline & LCI & $0.30 \pm 0.33$ & $\begin{array}{c}0.97 \pm \\
0.35 \\
\end{array}$ & $\begin{array}{c}0.28 \pm \\
0.15 \\
\end{array}$ & $\begin{array}{c}0.28 \pm \\
0.15 \\
\end{array}$ & $1.18 \pm 0.36$ & \\
\hline & LLI & $0.36 \pm 0.29$ & $\begin{array}{l}1.09 \pm \\
0.45 \\
\end{array}$ & $\begin{array}{l}0.30 \pm \\
0.12 \\
\end{array}$ & $\begin{array}{c}0.30 \pm \\
0.12 \\
\end{array}$ & $1.30 \pm 0.40$ & \\
\hline & LC & $0.32 \pm 0.27$ & $\begin{array}{l}1.24 \pm \\
0.48 \\
\end{array}$ & $\begin{array}{c}0.35 \pm \\
0.24 \\
\end{array}$ & $\begin{array}{c}0.35 \pm \\
0.24 \\
\end{array}$ & $1.54 \pm 0.39$ & \\
\hline & \multicolumn{6}{|c|}{$\begin{array}{c}\text { Table 4. Mean Gingival Thickness in Millimetres of } \\
\text { each Individual Tooth in Maxillary and Mandibular } \\
\text { Anterior Region }\end{array}$} & \\
\hline & \multicolumn{6}{|c|}{\begin{tabular}{|l} 
RC- Right Canine; RLI- Right Lateral Incisor; RCI- Right Central \\
Incisor; LCI - Left Central Incisor; LLI- Left Lateral Incisor; LC- \\
Left Canine
\end{tabular}} & \\
\hline
\end{tabular}

A total of 100 individuals (50 males and 50 females) participated in the study. However, in both the study groups, 
the difference between the mid buccal and mid inter papillary region in the maxillary and mandibular arches were statistically significant (Table 1 and 2). Also, the mean gingival thickness of the maxillary and mandibular anterior region between the Dravidian and Mongoloid population was statistically significant (Table 3$)(\mathrm{p} \leq 0.05)$. The mean gingival thickness of each maxillary and mandibular anterior tooth is tabulated in Table 4.

\section{DISCUSSION}

The thickness of palatal masticatory mucosa has been assessed by various techniques even though it has a less bearing as far as gingival recession or aesthetics is concerned. However, there is scanty literature evaluating the thickness of facial gingiva in the anterior maxillary and mandibular sextants that bears the maximum brunt of the gingival recession and has greater aesthetic relevance. Previously, several studies,11-14 have been conducted to evaluate the association if any, on the factors influencing thickness of gingiva in Indian population and they found that age and gender does have an effect on gingival phenotype. It was also believed that different racial populations may also influence gingival thickness. However, there are no studies reported in literature examining the racial influence in Indian population. In view of this, the current study was designed to explore the probable influence of racial backgrounds on gingival biotype in the Dravidian and Mongoloid racial groups of the Indian population.

The results of our study showed that the mean gingival thickness of the Dravidian group was $1.73 \pm 0.09 \mathrm{~mm}$ in maxilla and $1.40 \pm 0.15 \mathrm{~mm}$ in mandible whereas in the Mongoloid group it was $1.88 \pm 0.15 \mathrm{~mm}$ in maxilla and $1.60 \pm$ $0.18 \mathrm{~mm}$ in mandible which was statistically significant. Since, there was no data available on the influence of racioethnicity on gingival thickness in Dravidian and Mongoloids race groups no comparison with our results could be performed with existing data. Hence, an indirect comparison was carried out with similar kind of studies evaluating the racial influence on gingival thickness. In a study on a Caucasian population, the mean gingival thickness ranged from $0.40 \pm 0.07 \mathrm{~mm}$ to $0.72 \pm 0.11 \mathrm{~mm}$ in both arches. ${ }^{15}$ In a study of similar kind on the Indian population the mean gingival thickness ranged from $1.95 \pm 0.67 \mathrm{~mm}$ to $2.2 \pm 0.75$ $\mathrm{mm}{ }^{11}$ however, in this study no specific racio-ethnic group was mentioned. When the results of the present study; was compared to the aforementioned studies 11,15 it could be noted that the mean gingival thickness in the Dravidian and Mongoloid group who are sub types of the Indian population were more than the Caucasian population and less than the overall Indian population. Furthermore, a noteworthy finding in the current study is that among the two races; the Mongoloid group (Maxillary- $1.88 \pm 0.15 \mathrm{~mm}$; mandibular$1.40 \pm 1.5 \mathrm{~mm}$ ) had significantly higher gingival thickness compared to Dravidian group (Maxillary-1.73 $\pm 0.09 \mathrm{~mm}$; mandibular-1.40 $\pm 1.5 \mathrm{~mm}$ ). This indicates there is a possible influence of race on gingival thickness. Reasons for the differences can only be speculated. The possible explanation for this variation in thickness between the two groups as opposed to the overall population could be due to difference in the cellular activity, collagen production, basal metabolic activity, tyrosinase levels, water absorption rates, variation in keratinization, changes in oral epithelium in addition to the climatic and historical factors that may change the allele frequency among geographically distributed human populations. Another possible explanation is related to differences in the methods of measurement and measurement points. Hence, it can be assumed that there may be a positive racial influence on gingival thickness.

There is an array of invasive methods such as needles or probes ${ }^{5,16}$ cephalometric radiographs, ${ }^{17}$ transgingival probing 18 and direct visual assessment ${ }^{7}$ that are used to assess gingival biotype. Certain disadvantages of using these methods were inaccuracy in measurements as the values had to be rounded off to the nearest millimeter and the accumulation of local anaesthetic solution that may lead to bias in measuring the soft tissue thickness. Further, various non-invasive methods were also used such as ultrasonic devices ${ }^{19}$ and cone beam computed tomography (CBCT); but the drawbacks of these non-invasive methods were the nonreliable results obtained when the thickness of the gingiva exceeds $2-2.5 \mathrm{~mm}$, special training required to interpret the results and increased patient exposure to excessive radiation. ${ }^{13,19,20}$ In our study, we chose to use DVC even though it was invasive as it gave accurate measurements of point millimeter thickness with no special training to use the equipment and required only topical application of anaesthesia thereby eliminating the risk of bias. Also, further it had been reported that there was no significant difference between the radiographic measurements using CBCT scans and the clinical measurements using callipers. ${ }^{21}$ This highlighted the fact that measurements obtained by DVC used in our study were equivalent to high precision CBCT scans. However, caution should be excised while interpreting the results of our study due to certain inherent limitations. First, our study was limited to assessment on the labial mucosa and palatal mucosa was not considered. Second, confounding factor such as age which has an influence on thickness was not investigated. Third, these racial groups are diversely distributed and represent a greater subset of the Indian population. Due to the limited sample size and confined geographic location the sample in our study may not have been the true reflection of the selected race and ethnical group. Hence, the emphasis should now be focused on the correlation and comparison of race and ethnicity on gingival thickness in various racial groups in the world. In future, multistaged, multicentred longitudinal studies are necessary to validate our initial finding.

\section{CONCLUSIONS}

Within the limitations of the study it can be concluded that racio-ethnicity could have a positive influence on the gingival biotype. Clinicians should therefore take into consideration the possible influence of racial factor while determining the gingival biotype during the diagnostic and prognostic planning. 


\section{REFERENCES}

[1] Vandana KL, Gupta I. The relation of gingival thickness to dynamics of gingival margin position pre- and postsurgically. J Indian Soc Periodontol 2016;20(2):16773.

[2] Kan JYK, Rungcharassaeng K, Morimoto T, et al. Facial gingival tissue stability after connective graft with single immediate tooth replacement in the esthetic zone: consecutive case report. J Oral Maxillofac Surg 2009;67(Suppl 11):40-8.

[3] Evan CD, Chen ST. Esthetic outcomes of immediate implant placements. Clin Oral Implants Res 2008;19(1):73-80.

[4] Pontoriero R, Carnevale G. Surgical crown lengthening: a 12 month clinical wound healing study. J Periodontol 2001;72(7):841-8.

[5] Olsson $M$, Lindhe J. Periodontal characteristics in individuals with varying form of the upper central incisors. J Clin Periodontol 1991;18(1):78-82.

[6] Kao RT, Fagan MC, Conte GJ. Thick vs thin gingival biotypes: a key determinant in treatment planning for dental implants. J Calif Dent Assoc 2008;36(3):193-8.

[7] Seibert J, Lindhe J. Textbook of Clinical periodontology and implant dentistry. $2^{\text {nd }}$ edn. Copenhangen: Munksgaard 1989: p. 477-517.

[8] Muller HP, Eger T. Gingival phenotype in young male adults. J Clin Periodontol 1997;24(1):65-71.

[9] Saksena N. Ginigival biotype linked to racio-ethnicity: Southern region of Asian subcontinent. Oral Health \& Dent Manag 2015;14:4.

[10] Studer SP, Allen EP, Rees TC, et al. The thickness of masticatory mucosa in the human hard palate and tuberosity as potential donor sites for ridge augmentation procedures. J Periodontol 1997;68(2):145-51.
[11] Vandana KL, Savitha B. Thickness of gingiva in association with age, gender and dental arch location. J Clin Periodontol 2005;32(7):828-30.

[12] Wara-aswapati N, Pitiphat W, Chandrapho N, et al. The thickness of palatal masticatory mucosa associated with age. J Periodontol 2001;72(10):1407-12.

[13] Kan JYK, Morimoto T, Rungcharassaeng K, et al. Gingival biotype assessment in the esthetic zone: Visual versus direct measurement. Int J Periodontics Restorative Dent 2010;30(3):237-43.

[14] Goaslind GD, Robertson PB, Mahan CJ, et al. Thickness of facial gingiva. J Periodontol 1977;48(12):768-71.

[15] Fischer KR, Richter $T$, Kebschull $M$, et al. On the relationship between gingival biotypes and gingival thickness in young Caucasians. Clin. Oral Implants Res 2015;26(8):865-9.

[16] Claffey N, Shanley D. Relationship of gingival thickness and bleeding to loss of probing attachment in shallow sites following non-surgical periodontal therapy. J Clin Periodontol 1986;13(7):654-7.

[17] Ostlund SG. The effect of complete dentures on the gum tissues: a histological and histopathological investigation. Acta Odontol Scand 1958;16(1):1-41.

[18] Muller HP, Heinecke A, Schaller N, et al. Masticatory mucosa in subject with different periodontal phenotypes. J Clin Periodontol 2000;27(9):621-6.

[19] Baldi C, Pini-Prato G, Pagliaro U, et al. Coronally advanced flap procedure for root coverage. Is flap thickness a relevant predictor to achieve root coverage? A 19-case series. J Periodontol 1999;70(9):1077-84.

[20] Misch KA, Yi ES, Sarment DP. Accuracy of cone beam computed tomography for periodontal defect measurements. J Periodontol 2006;77(7):1261-6. 